\title{
Plasmodium knowlesi and other malaria parasites in long-tailed macaques from the Philippines
}

Lief Erikson Gamalo ${ }^{1,2}$, Judeline Dimalibot ${ }^{1}$, Khamisah Abdul Kadir $^{3}$, Balbir Singh ${ }^{3^{*}}$ (10 and Vachel Gay Paller ${ }^{\text {* }^{*}}$

\begin{abstract}
Background: Macaca fascicularis (long-tailed macaque) is the most widespread species of macaque in Southeast Asia and the only species of monkey found naturally in the Philippines. The species is the natural host for the zoonotic malaria species, Plasmodium knowlesi and Plasmodium cynomolgi and for the potentially zoonotic species, Plasmodium inui. Moreover, other Plasmodium species such as Plasmodium coatneyi and Plasmodium fieldi are also natural parasites of $M$. fascicularis. The aims of this study were to identify and determine the prevalence of Plasmodium species infecting wild and captive long-tailed macaques from the Philippines.

Methods: A total of 95 blood samples from long-tailed macaques in the Philippines were collected from three locations; 30 were from captive macaques at the National Wildlife Rescue and Rehabilitation Center (NWRRC) in Luzon, 25 were from captive macaques at the Palawan Wildlife Rescue and Conservation Center (PWRCC) in Palawan and 40 were from wild macaques from Puerto Princesa Subterranean River National Park (PPSRNP) in Palawan. The Plasmodium spp. infecting the macaques were identified using nested PCR assays on DNA extracted from these blood samples.
\end{abstract}

Results: All 40 of the wild macaques from PPSRNP in Palawan and 5 of 25 captive macaques from PWRCC in Palawan were Plasmodium-positive; while none of the 30 captive macaques from the NWRRC in Luzon had any malaria parasites. Overall, P. inui was the most prevalent malaria parasite (44.2\%), followed by P. fieldi (41.1\%), P. cynomolgi (23.2\%), P. coatneyi (21.1\%), and P. knowlesi (19\%). Mixed species infections were also observed in 39 of the 45 Plasmodium-positive macaques. There was a significant difference in the prevalence of $P$. knowlesi among the troops of wild macaques from PPSRNP.

Conclusion: Wild long-tailed macaques from the island of Palawan, the Philippines are infected with $P$. knowlesi, $P$. inui, P. coatneyi, P. fieldi and P. cynomolgi. The prevalence of these Plasmodium spp. varied among the sites of collection and among troops of wild macaques at one site. The presence of these simian Plasmodium parasites, especially $P$. knowlesi and P. cynomolgi in the long-tailed macaques in Palawan presents risks for zoonotic transmission in the area.

Keywords: Simian Plasmodium, Macaca fascicularis, Palawan, Plasmodium knowlesi

\footnotetext{
*Correspondence: bsingh@unimas.my; vvpaller@up.edu.ph

${ }^{1}$ Animal Biology Division, Institute of Biological Sciences, University

of the Philippines Los, Baños, 4031 Los Baños, Laguna, Philippines

${ }^{3}$ Malaria Research Centre, Faculty of Medicine and Health Sciences,

Universiti Malaysia Sarawak, 94300 Kota Samarahan, Sarawak, Malaysia

Full list of author information is available at the end of the article
} 


\section{Background}

Over 150 species of Plasmodium have been described infecting vertebrate terrestrial animals [1]. Twenty-six species of the genus infect non-human primate hosts [2] and 13 of these infect non-human primates in South East Asia [3]. Four species of Plasmodium (Plasmodium falciparum, Plasmodium vivax, Plasmodium malariae, and Plasmodium ovale spp.), were thought to cause malaria in humans until Plasmodium knowlesi, a parasite that infects Macaca spp. in nature, was discovered to be commonly infecting humans in the Kapit Division of Sarawak, Malaysian Borneo [4]. Subsequent studies have shown that human cases occur throughout South East Asia [5, 6] and on the Nicobar and Andaman islands of India [7].

Other than P. knowlesi, natural human infections with the simian malaria parasite Plasmodium cynomolgi have been described in Peninsular Malaysia [8] and Cambodia [9]. A third malaria parasite of macaques, Plasmodium inui, was accidentally transmitted to humans in laboratories by mosquito bites and subsequently shown to be infectious under experimental conditions [2]. Thus, monitoring the natural hosts of these non-human primate Plasmodium parasites should be given attention as they are the potential reservoir hosts for malaria infections in humans [10-14].

Long-tailed macaques (Macaca fascicularis), the only monkey species in the Philippines, are widely distributed in the country, with sightings on the islands of Balabac, Basilan, Biliran, Bohol, Busuanga, Camiguin, Catanduanes, Culion, Leyte, Luzon, northeastern Mindanao, Mindoro, Negros, Panay, Palawan, Samar and Sibuyan [15]. This species can be naturally infected by 6 Plasmodium species, namely P. knowlesi, Plasmodium fieldi, Plasmodium coatneyi, P. cynomolgi, P. inui and Plasmodium simiovale [16]. In a recent study, using molecular techniques, $P$. cynomolgi and $P$. coatneyi were detected in long-tailed macaques from Batangas, and P. cynomolgi, $P$. coatneyi and $P$. inui in macaques from Zamboanga, the Philippines [17]. Of all the Philippine islands where M. fascicularis are distributed, P. knowlesi infected macaques have only been reported previously in Palawan Island in 1978 and Cebu Island in 1961 [18, 19]. Other simian Plasmodium species such as $P$. inui, $P$. cynomolgi and $P$. coatneyi, were described in long-tailed macaques in Palawan island but the observation was solely based on morphological examination of the blood smears from the macaques [19]. With the use of molecular detection methods, human cases of $P$. knowlesi infection have been reported in Palawan Island from five local inhabitants [20] and visitors from Taiwan, Japan and USA [21-23].

The overall aim of this study was to identify Plasmodium species and their prevalence in long-tailed macaques ( $M$. fascicularis) from Luzon and Palawan
Islands. Specifically, the study aimed to identify the Plasmodium species in long-tailed macaques using molecular techniques, determine the prevalence of Plasmodium parasites from both wild and captive macaques, and compare prevalence of Plasmodium spp. among various sites of collection and between different troops of wild macaques.

\section{Methods \\ Collection of samples}

A total of 95 blood samples were obtained from longtailed macaques at the Puerto Princesa Subterranean River National Park (PPSRNP) and the Palawan Wildlife Rescue and Conservation Center (PWRCC) in Palawan, and from the National Wildlife Rescue and Research Center (NWRRC) in Quezon City (Fig. 1) during the month of August and September 2017.

There are approximately 500 free-ranging long-tailed macaques at PPSRNP and humans constantly encounter them. The area is characterized by the presence of beach forest, karst forest, secondary forest and mangrove forest. These diverse habitats offer long-tailed macaques the locations to feed, roost and breed. The area is also near to human settlements and recreation areas. The trapping site was also characterized by presence of park personnel who live within the premises of the Central Park Station. A total of 40 wild macaques were trapped at PPSRNP and they were from three troops (11 from troop 1, 18 from troop 2 and 11 from troop 3). Although troops 1 and 2 have overlapping territories, they have different sleeping sites. The territory of troop 3 was approximately $2 \mathrm{~km}$ from that of troops 1 and 2 . The 25 macaques at PWRCC and 30 at the NWRRC were all captive macaques. In Palawan, rescued macaques are rehabilitated in the PWRCC located in the South of the Puerto Princesa City. Macaques donated and rescued from the main island Luzon are placed in the NWRRC located in Diliman, Quezon City. Both rescue centers provide shelter for animals confiscated or donated from illegal traders and from private owners.

The macaques were tranquilized, anesthetized intramuscularly with Zoletil ( $5 \mathrm{mg} / \mathrm{kg}$ body weight) before the blood samples were collected as specified in the approved IACUC clearance. Blood samples (maximum of $3 \mathrm{ml}$ per animal) were collected using a syringe from the femoral vein of the macaques into a tube with ethylenediaminetetraacetic acid (EDTA). From the EDTA tubes, three blood spots for each sample were transferred $(40-50 \mu \mathrm{L}$ each) to Whatman $3 \mathrm{MM}$ filter papers in situ. The samples were initially kept at room temperature $\left(20-29^{\circ} \mathrm{C}\right)$ for 7-45 days and were transported to ABD Parasitology Laboratory in UPLB and kept refrigerated at $4{ }^{\circ} \mathrm{C}$. Blood spots on filter papers were transported to the Malaria 

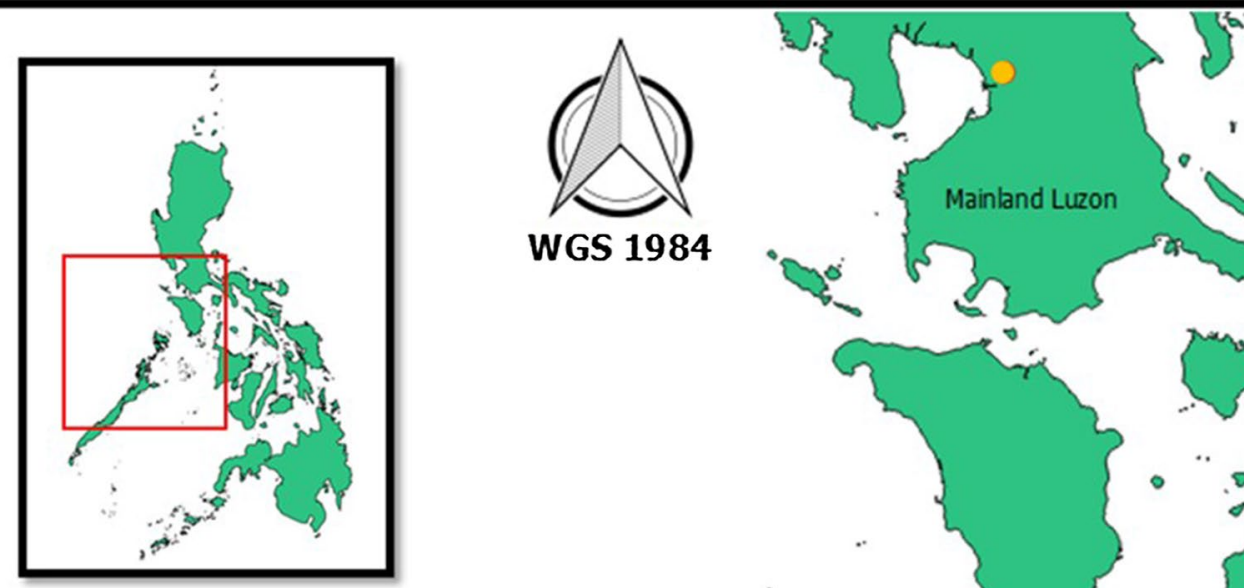

Legend

- Captive macaques

- Wild macaques

PPSRNP Boundary

Palawan

Philippine Islands

WGS 1984 Mainland Luzon

0

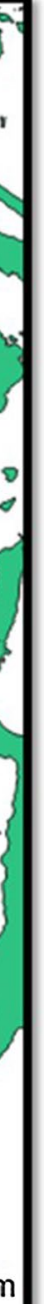

3

ᄂ

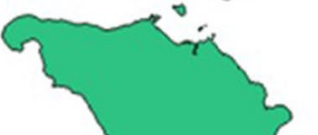

.
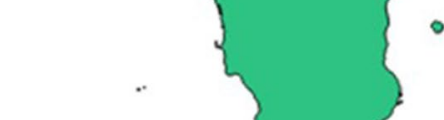

.

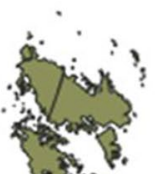

. 8 .

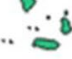

$\begin{array}{llllll}50 & 0 & 50 \quad 100 & 150 \quad 200 \mathrm{~km}\end{array}$

Fig. 1 Location of the sampling sites. Wild macaques from Puerto Princesa Subterranean River National Park (PPSRNP) (blue dot), and captive macaques from Palawan Wild life Rescue and Conservation Center in Palawan (PWRCC) (red dot) and National Wildlife Rescue and Research Center (NWRRC) (orange dot), Philippines. Generated using QGIS version 2.3

Research Centre, Universiti Malaysia Sarawak, Kota Samarahan, Sarawak, Malaysia for DNA extraction and the molecular analysis.

Gratuitous permits were given by the Palawan Council for Sustainable Development (PCSD) (Permit No.: 201707) and from the Biodiversity Management Bureau (Permit No.: 266) to collect blood samples from the island of Palawan and from the NWRRC in Luzon, respectively. Ethics clearance was obtained from the Institutional Animal Care and Use Committee (IACUC) of the University of the Philippines Los Baños (Protocol No.: 2017-0044). The clearance to conduct the study in a protected area was given by the Protected Area Management Board of
PPSRNP (Resolution No.: 11-2017). Export and import permits were secured from PCSD (Permit No.: 00003A2017) and BMB (Permit No.: 23568 A-2017), and Sarawak Forestry Department, Sarawak, Malaysia (Permit No.: 17513), respectively.

\section{Analysis of samples}

DNA was extracted from blood spots in filter papers at the Malaria Research Centre, Universiti Malaysia Sarawak with the use of InstaGene (InstaGene Matrix, Bio-Rad Laboratories, USA) as described previously [24]. This was followed by examining the samples using nested PCR assays with the use of genus and species-specific 
primers based on the small subunit ribosomal RNA gene. The DNA samples was first examined with the aid of genus-specific primers (rPLU1 and rPLU5, and rPLU3 and rPLU4) as described previously [25]. Positive samples were then examined by nested PCR assays using the species-specific primers to detect $P$. knowlesi, P. coatneyi, $P$. cynomolgi, P. inui and $P$. fieldi as described previously [26]. The products of the amplification were analysed by gel electrophoresis in $2.7 \%$ agarose gels and were stained by Sybersafe before being observed under UV light.

\section{Statistical analysis}

Fisher-Freeman-Halton exact test was used to compute the exact probabilities of the differences of the prevalence of Plasmodium prevalence rate between habitats (site of collection) and among troops of wild macaques. All statistics were tested using SPSS. Statistical significance for all tests was set at $\mathrm{P}<0.05$.

\section{Results}

Of the 95 long-tailed macaque samples examined by nested PCR assays, $47.4 \%$ were positive for Plasmodium spp. (Table 1). Five species of Plasmodium were detected; P. cynomolgi, P. inui, P. coatneyi P. fieldi and P. knowlesi (Table 1). Plasmodium inui was the most prevalent (44.2\%), followed by P. fieldi (41\%), P. cynomolgi (23.2\%), P. coatneyi (21\%) and P. knowlesi (19\%). A majority of the macaques $(86.6 \% ; 39 / 45)$ had multiple infections; 8 double infections (8.4\%), 13 triple (13.7\%), 10 quadruple $(10.5 \%)$, and $8(8.4 \%)$ of them were infected by 5 species of Plasmodium.

The prevalence of each Plasmodium spp. among the macaques varied significantly for the sites of collection.
All wild macaques from PPSRNP were infected with malaria parasites compared with only 5 of the $25(20 \%)$ captive macaques from PWRCC and none of the captive ones at NWRRC (Fisher-Freeman-Halton exact test 98.013, $\mathrm{P}=0.0001,95 \%$ CI 0.000-0.031). When tested if the prevalence of $P$. knowlesi differs from one macaque troop to another at PPSRNP, troop 2 (Fisher-FreemanHalton exact test $6.779, \mathrm{P}=0.03,95 \%$ CI $0.000-0.157$ ) showed a lower prevalence compared to troops 1 and 3 (Table 2).

\section{Discussion}

In the present study, all of the 40 wild macaques sampled from PPSRNP were infected with Plasmodium spp. and there was a $20 \%$ infection rate among captive macaques at PWRCC. The presence of Plasmodium spp. in PWRCC could suggest that competent vectors could be present at the site. However, it is also possible that the macaques were already infected by Plasmodium before they were transported to the rehabilitation centre. No malaria parasites were observed in captive macaques from NWRRC, which is located in Manila, a highly urbanized area.

\begin{tabular}{|c|c|c|c|c|}
\hline Troops & $\begin{array}{l}\text { Estimated no. } \\
\text { of members }\end{array}$ & $\begin{array}{l}\text { Collected } \\
\text { samples }\end{array}$ & Sleeping sites & $\begin{array}{l}\text { Prevalence } \\
\text { of } P \text {. knowlesi } \\
(\%)\end{array}$ \\
\hline 1 & 52 & 11 & Inside forest & 63.6 \\
\hline 2 & 43 & 18 & Beside beach & 22.2 \\
\hline 3 & 46 & 11 & Inside forest & 63.6 \\
\hline
\end{tabular}

Table 1 Plasmodium species infecting long-tailed macaques in Palawan, Philippines

\begin{tabular}{|c|c|c|c|c|c|c|}
\hline Infection & Plasmodium spp. & PPSRNP $(n=40)$ & PWRCC $(n=25)$ & NWRRC $(n=30)$ & $\begin{array}{l}\text { Total } \\
\text { Plasmodium- } \\
\text { positive }\end{array}$ & Prevalence (\%) \\
\hline \multirow[t]{2}{*}{ Single } & Pin & 2 & 2 & - & 4 & 6.3 \\
\hline & $\mathrm{Pk}$ & 2 & - & - & 2 & \\
\hline \multirow[t]{2}{*}{ Double } & Pin, Pfld & 4 & 3 & - & 7 & 8.4 \\
\hline & Pct, Pfld & 1 & - & - & 1 & \\
\hline \multirow[t]{3}{*}{ Triple } & Pcy, Pin, Pfld & 7 & - & - & 7 & 13.7 \\
\hline & Pct, Pin, Pfld & 3 & - & - & 3 & \\
\hline & Pk, Pin, Pfld & 3 & - & - & 3 & \\
\hline \multirow[t]{3}{*}{ Quadruple } & Pcy, Pct, Pin, Pfld & 5 & - & - & 5 & 10.5 \\
\hline & Pk, Pcy, Pin, Pfld & 3 & - & - & 3 & \\
\hline & Pk, Pct, Pin, Pfld & 2 & - & - & 2 & \\
\hline Quintuple & Pk, Pcy, Pct, Pin, Pfld & 8 & - & - & 8 & 8.4 \\
\hline \multicolumn{2}{|c|}{ Total Plasmodium-positive (\%) } & $40(100)$ & $5(20)$ & $0(0)$ & $45(47.4)$ & \\
\hline
\end{tabular}

Pin, P. inui; Pk, P. knowlesi; Pct, P. coatneyi; Pcy, P. cynomolgi; Pfld, P. fieldi; PPSRNP, Puerto Princesa Subterranean River National Park; PWRCC, Palawan Wildlife Rescue and Conservation Center; NWRRC, National Wildlife Rescue and Research Center 
Most of the macaques from these rescue centers were reported to be confiscated or donor pets. The absence of any Plasmodium species in macaques in NWRRC could be due to lack of competent vectors of malaria in urbanized areas as what was also observed in Singapore where wild macaques from a forested area had malaria parasites while peri-domestic macaques had none [27]. Similarly in a study in Peninsular Malaysia it was found that there were no parasites present in long-tailed macaques living in urban areas whereas monkeys caught in the forested areas were infected with simian malaria parasites [28].

In PPSRNP, various wild macaque troops were observed and samples were obtained from 3 different troops. A limitation of the present study is that the sample size of 95 monkeys and 45 malaria-positives (with 40 from PPSRNP) is relatively small. Nevertheless, differences in prevalence of malaria parasites were observed between the troops. The lower prevalence of each Plasmodium species in troop 2 compared to the other two troops could be the effect of the choice of each troop's sleeping sites. Troop 2 was observed to sleep on the trees approximately $4 \mathrm{~m}$ away from the sea front. In contrast, Troop 1 and 3 were observed to sleep inside the forests, and hence were probably more vulnerable to mosquito species which tend to prefer shaded areas in the forest as breeding sites [29].

The presence of the multiple species of Plasmodium detected in the macaques by nested PCR assays confirms the previous observations of the complex nature of simian Plasmodium parasites in long-tailed macaques [17, $26,27,30]$. The prevalence of multiple infections in wild long-tailed macaques $(86.6 \%)$ was observed to be lower in this study compared to the $92.6 \%$ observed for macaques in Sarawak, Malaysian Borneo [26], but is higher than that found in studies conducted in Peninsular Malaysia (74.3\%) [30] and Singapore (42.42\%) [27]. Because of this complexity of mixed species infections, it is very difficult to accurately identify the Plasmodium species infecting long-tailed macaques through microscopic examination alone, since the early trophozoites of all the simian malaria parasites and the late trophozoites of some species of Plasmodium are morphologically identical, making it difficult to differentiate one species from another [2]. In a report from Taiwan, molecular analysis confirmed that the previously thought $P$. knowlesi and P. cynomolgi isolates where actually $P$. inui [10], underscoring the importance of using molecular detection methods for identification of the various species of Plasmodium.

In the present study, $P$. inui was the most prevalent Plasmodium species detected, similar to what was found in the studies conducted in Sarawak and Sabah in Malaysian Borneo, and in Selangor, Peninsular Malaysia, respectively $[26,30]$. The species was also found to have the highest prevalence in a study of macaques in Thailand [31], but the lowest in the study of long-tailed macaques conducted in Singapore [27]. In the present study, P. fieldi showed a higher prevalence compared to $P$. cynomolgi, $P$. knowlesi and $P$. coatneyi, while it was not detected in a previous study of long-tailed macaques from Batangas, Zamboanga and Palawan in the Philippines $[17,19]$. The reasons for this observation are unclear since similar PCR assays were used in previous studies $[17,26,27,30]$ and this further highlights that there are major differences in the prevalence of each of the simian Plasmodium species in macaques from different geographical locations. Plasmodium cynomolgi also showed a relatively high prevalence in PPSRNP and this species has been reported to naturally infect humans $[8,9]$. Plasmodium cynomolgi, $P$. inui and $P$. coatneyi were recorded in macaques in Palawan through microscopy several decades ago [19] and molecular identification done in the current study confirmed that these parasites are indeed currently occurring in long-tailed macaques in the island of Palawan. Moreover, for the first time, the current study records the existence of $P$. fieldi in the country, indicating that longtailed macaques on the island of Palawan, Philippines are natural hosts for P. cynomolgi, P. inui, P. coatneyi, P. fieldi and $P$. knowlesi.

The presence of $P$. knowlesi and the other potentially zoonotic simian Plasmodium parasites such as $P$. cynomolgi $[8]$ and $P$. inui species $[32,33]$ are potential threats to the local people in Palawan. The first report of human knowlesi malaria cases in Palawan was made by Luchavez et al. in 2008 [20] of 5 human cases occurring in 2006 and 2007, including one case in San Miguel, which is only $30 \mathrm{~km}$ from PPSNRP. Subsequently two travelers from Taiwan and USA to Palawan island were found to be infected with P. knowlesi in 2009 [21]. There have been no other human knowlesi malaria cases reported in the local population of Palawan Island since 2008 despite 54,314 malaria cases being detected by microscopy in the province from 2009 to 2017; 76\% P. falciparum, $16.5 \%$ P. vivax, $1.4 \%$ P. malariae, $3.4 \%$ mixed species and $2.6 \%$ with no data of Plasmodium species available (unpublished data from Kilusan Ligtas Malaria [Movement Against Malaria], Provincial Government of Palawan). The lack of reports of $P$. knowlesi cases during this period among the local population is most probably due to the use of microscopy rather than molecular detection methods for routine diagnosis of malaria in Palawan Island. Misdiagnosis of $P$. knowlesi as $P$. falciparum or $P$. malariae by microscopy could have occurred since the early trophozoites of $P$. knowlesi resemble those of $P$. falciparum while the mature blood stages and gametocytes of $P$. knowlesi are similar to those of $P$. malariae [6]. In Malaysia, where the local population is infected with $P$. 
knowlesi, $P$. falciparum and $P$. vivax, infections with $P$. knowlesi have not only been misdiagnosed as $P$. malariae or $P$. falciparum but also as $P$. vivax by microscopy $[4,34,35]$. Although there have been no local human knowlesi malaria cases reported in Palawan island since Luchavez and co-workers reported the five cases in 2008 [20] and the travelers from Taiwan and USA who acquired knowlesi malaria the following year, there was a recent case report of a Japanese man who got infected with $P$. knowlesi during his 3 month stay at a forest resort Palawan in 2018 [22]. He was diagnosed 5 days upon his return to Japan, where a blood film revealed parasites resembling $P$. malariae or $P$. knowlesi, and a diagnosis of P. knowlesi was made following analysis by nested PCR assays. This strongly suggests that local cases of knowlesi malaria in Palawan have been occurring since 2008 but have been misdiagnosed by microscopy as $P$. falciparum or $P$. malariae. Given that long-tailed macaques in Palawan island are infected with $P$. knowlesi and P. cynomolgi, there is a need to use molecular detection methods to undertake large scale epidemiological studies in Palawan island to determine the true prevalence of zoonotic malaria among the local population. Entomological studies also need to be conducted to identify the mosquito vectors responsible for transmission of simian malaria.

Deforestation and agricultural expansion are identified as the key drivers of $P$. knowlesi infection in humans [36]. This happens when natural habitats of the reservoir hosts are reduced or the feeding behavior of the vectors of the parasites are altered which will eventually result in high transmission of the parasite from one host to another. Long-tailed macaques are said to increase density as response to deforestation, which increases the possibility of contact from one individual to another [36] and will encroach human in settlements [28]. Although PPSRNP is a protected area and deforestation is prohibited, there is a visible increase of human-macaque interaction in the area due to tourism and other activities by the locals, hence posing threats of zoonotic transmission of both $P$. knowlesi and P. cynomolgi to the local population.

\section{Conclusion}

The presence of P. knowlesi, P. cynomolgi, P. inui and $P$. coatneyi in long-tailed macaques in Palawan island was confirmed using molecular detection assays. The study also reports the first detection of $P$. fieldi in macaques in the Philippines. The prevalence of Plasmodium spp. varied among the sites of collection and even among troops of wild macaques from one site. The presence in wild macaques of these simian Plasmodium parasites, especially $P$. knowlesi and $P$. cynomolgi, presents risks to the local people in Palawan island.

\section{Abbreviations}

BMB: Biodiversity Management Bureau; IACUC: Institutional Animal Care and Use Committee; NWRRC: National Wild life Rescue and Rehabilitation Center; PCSD: Palawan Council for Sustainable Development; PPSRNP: Puerto Princesa Subterranean River National Park; PWRCC: Palawan Wild life Rescue and Conservation Center; PCR: polymerase chain reaction.

\section{Authors' contributions}

VGP and BS conceptualized the study. LEG, BS, VGP, and JCD participated in the study design and secured the permits and clearances in the Philippines and Malaysia. LEG conducted the field work, and with KAD undertook the molecular analysis of the samples in Malaysia. LEG, VGP and BS wrote the paper. All authors read and approved the final manuscript.

\section{Author details \\ ${ }^{1}$ Animal Biology Division, Institute of Biological Sciences, University of the Philippines Los, Baños, 4031 Los Baños, Laguna, Philippines. ${ }^{2}$ Present Address: Department of Biological Sciences and Environmental Studies, University of the Philippines Mindanao, Tugbok District, Mintal, 8000 Davao City, Philippines. ${ }^{3}$ Malaria Research Centre, Faculty of Medicine and Health Sci- ences, Universiti Malaysia Sarawak, 94300 Kota Samarahan, Sarawak, Malaysia.}

\section{Acknowledgements}

The authors would like to thank Biodiversity Management Bureau-Department of Environment and Natural Resources (BMB-DENR), Palawan Council for Sustainable Development (PCSD) and the Sarawak Forestry Department for the permits. The authors would like to thank the managements of the Puerto Princesa Subterranean River National Park, National Wildlife Rescue and Rehabilitation Center and Palawan Wildlife Rescue and Conservation Center administrators and staff for the assistance and support in during the sampling periods

Competing interests

The authors declare that they have no competing interests.

Availability of data and materials

Not applicable.

\section{Consent for publication}

All authors have seen and approved the manuscript and its contents, and have agreed to submission for publication.

\section{Ethics approval}

Ethical approval for this work was obtained from the Institutional Animal Care and Use Committee of the College of Veterinarians, University of the Philippines Los Baños (Protocol No.: 2017-0044).

\section{Funding}

This work was funded through research grants and scholarships from the Philippine Department of Science and Technology (DOST) to LEG, as well as the Office of International Linkages-Continuous Operational and Outcomes-based Partnership for Excellence in Research and Academic Training Enhancement (OIL-COOPERATE) grant of the University of the Philippines to LEG and VGP, and by a Top-Down Research Grant (05-FA052000-0606-002) from Universiti Malaysia Sarawak to BS.

\section{Publisher's Note}

Springer Nature remains neutral with regard to jurisdictional claims in published maps and institutional affiliations.

Received: 5 February 2019 Accepted: 13 April 2019

Published online: 24 April 2019

\section{References}

1. Garnham PCC. Malaria parasites and other haemosporidia. Oxford: Blackwell Scientific Publication; 1966.

2. Coatney RG, Collins WE, McWilson W, Contacos PG. The primate malarias. Washington, DC: National Institutes of Health, Bethesda; 1971. 
3. Collins WE. Major animal models in malaria research: Simian. In: Wernsdorfer WH, McGregor I, editors. Malaria principles and practice of malariology, vol. 2. London: Edinburgh Churchill Livingstone; 1988. p. 1474-501.

4. Singh B, Sung LK, Matusop A, Radhakrishnan A, Shamsul SSG, Cox-singh J, et al. A large focus of naturally acquired Plasmodium knowlesi infections in human beings. Lancet. 2004;363:1017-24.

5. Conlan JV, Sripa B, Attwood S, Newton PN. A review of parasitic zoonoses in a changing Southeast Asia. Vet Parasitol. 2011;182:22-40.

6. Singh B, Daneshvar C. Human infections and detection of Plasmodium knowlesi. Clin Microbiol Rev. 2013;26:165-84.

7. Sunish IP, Shriram A, Vijayachari P. Malaria in the Andaman and Nicobar Islands: challenges and opportunities for elimination. Asian Pacific J Trop Dis. 2015;5:837-40.

8. Ta TH, Hisam S, Lanza M, Jiram Al, Ismail N, Rubio JM. First case of a naturally acquired human infection with Plasmodium cynomolgi. Malar J. 2014;13:68.

9. Imwong M, Madmanee W, Suwannasin K, Kunasol C, Peto TJ, Tripura R, et al. Asymptomatic natural human infections with the simian malaria parasites Plasmodium cynomolgi and Plasmodium knowlesi. J Infect Dis. 2018:219:695-702.

10. Huang C-C, Ji D-D, Chiang Y-C, Teng H-J, Liu H-J, Chang C-D, et al. Prevalence and molecular characterization of Plasmodium inui among Formosan macaques (Macaca cyclopis) in Taiwan. J Parasitol. 2010;96:8-15.

11. Deane LM. Simian malaria in Brazil. Mem Inst Oswaldo Cruz. 1992;87(Suppl 3):1-20.

12. Lourenço-de-Oliveira R, Deane LM. Simian malaria at two sites in the Brazilian Amazon. I. The infection rates of Plasmodium brasilianum in nonhuman primates. Mem Inst Oswaldo Cruz. 1995;90:331-9.

13. Cox FEG. History of the discovery of the of the malaria parasites and their vectors. Parasit Vectors. 2010;3:5.

14. Baird JK. Malaria zoonoses. Travel Med Infect Dis. 2009;7:269-77.

15. Ong P, Richardson M. Macaca fascicularis, crab-eating Macaque. IUCN Red List Threat Species. IUCN 2008:T12551A3355536. 2015.

16. Nada Raja T, Hu TH, Zainudin R, Lee KS, Perkins SL, Singh B. Malaria parasites of long-tailed macaques in Sarawak, Malaysian Borneo: a novel species and demographic and evolutionary histories. BMC Evol Biol. 2018:18:49.

17. Zhang X, Kadir KA, Quintanilla-Zariñan LF, Villano J, Houghton P, Du H, et al. Distribution and prevalence of malaria parasites among long-tailed macaques (Macaca fascicularis) in regional populations across Southeast Asia. Malar J. 2016;15:450.

18. Lambrecht FL, Dunn FL, Eyles DE. Isolation of Plasmodium knowlesi from Philippine macaques. Nature. 1961;191:1117-8.

19. Tsukamoto M, Miyata A. Surveys on simian malaria parasites and their vector in Palawan island, the Philippines. Trop Med. 1978;20:39-50.

20. Luchavez J, Espino F, Curameng P, Espina R, Bell D, Chiodini P, et al. Human infections with Plasmodium knowlesi, the Philippines. Emerg Infect Dis. 2008;14:811-3.

21. Kuo M, Chiang T, Tsai W. A case report of simian malaria, Plasmodium knowlesi, in a Taiwanese traveler from Palawan island, the Philippines. Taiwan Epidemiol Bull. 2009;25:178-91.
22. Takaya S, Kutsuna S, Suzuki T, Komaki-yasuda K, Kano S, Ohmagari N. Plasmodium knowlesi infection with rhabdomyolysis in a Japanese traveler to Palawan, the Philippines. Am J Trop Med Hyg. 2018;99:967-9.

23. Mali S, Steele S, Slutsker L, Arguin PM. Malaria surveillance-United States, 2008. MMWR Surveill Summ. 2010;59:1-15.

24. Cox-Singh J, Mahayet S, Abdullah MS, Singh B. Increased sensitivity of malaria detection by nested polymerase chain reaction using simple sampling and DNA extraction. Int J Parasitol. 1997;27:1575-7.

25. Singh B, Bobogare A, Cox-Singh J, Snounou G, Abdullah MS, Rahman HA. A genus-and species-specific nested polymerase chain reaction malaria detection assay for epidemiologic studies. Am J Trop Med Hyg. 1999;60:687-92.

26. Lee KS, Divis PCS, Zakaria SK, Matusop A, Julin RA, Conway DJ, et al. Plasmodium knowlesi: reservoir hosts and tracking the emergence in humans and macaques. PLoS Pathog. 2011;7:e1002015.

27. Lim I. Identification and molecular characterisation of simian malaria parasites in wild monkeys of Singapore. M.Sc. Thesis, National University of Singapore. 2011.

28. Vythilingam I, Noorazian YM, Huat TC, Jiram Al, Yusri YM, Azahari AH, et al. Plasmodium knowlesi in humans, macaques and mosquitoes in peninsular Malaysia. Parasit Vectors. 2008;1:26.

29. Vythilingam I, Hii J. Simian malaria parasites: special emphasis on Plasmodium knowlesi and their Anopheles vectors in Southeast Asia. In: Manguin $\mathrm{S}$, editor. Anopheles mosquitoes-new insights into malaria vectors. London: IntechOpen; 2013. p. 407-510.

30. Akter R, Vythilingam I, Khaw LT, Qvist R, Lim YAL, Sitam FT, et al. Simian malaria in wild macaques: first report from Hulu Selangor district, Selangor, Malaysia. Malar J. 2015;14:386

31. Putaporntip C, Jongwutiwes S, Thongaree S, Seethamchai S, Grynberg P, Hughes A. Ecology of malaria parasites infecting Southeast Asian macaques: evidence from cytochrome b sequences. Mol Ecol. 2010;19:3466-74

32. Coatney GR. Simian malaria infection. J Am Med Assoc. 1963;184:876-7.

33. Coatney GR, Chin W, Contacos PG, King HK. Plasmodium inui, a quartantype old world monkeys transmissible To man. J Parasitol. 1966;52:660-3.

34. Cox-Singh J, Davis TME, Lee K-S, Shamsul SSG, Matusop A, Ratnam S, et al. Plasmodium knowlesi malaria in humans is widely distributed and potentially life threatening. Clin Infect Dis. 2008:46:165-71.

35. Barber BE, William T, Grigg MJ, Yeo TW, Anstey NM. Limitations of microscopy to differentiate Plasmodium species in a region co-endemic for Plasmodium falciparum, Plasmodium vivax and Plasmodium knowlesi. Malar J. 2013:12:8.

36. Fornace KM, Abidin TR, Alexander N, Brock P, Grigg MJ, Murphy A, et al. Association between landscape factors and spatial patterns of Plasmodium knowlesi infections in Sabah, Malaysia. Emerg Infect Dis J. 2016:22:201-8

\footnotetext{
Ready to submit your research? Choose BMC and benefit from:

- fast, convenient online submission

- thorough peer review by experienced researchers in your field

- rapid publication on acceptance

- support for research data, including large and complex data types

- gold Open Access which fosters wider collaboration and increased citations

- maximum visibility for your research: over $100 \mathrm{M}$ website views per year
}

At BMC, research is always in progress.

Learn more biomedcentral.com/submissions 